\title{
Indian-nut (Aleurites moluccana) and tucum (Astrocaryum vulgare), non agricultural sources for biodiesel production using ethanol: composition, characterization and optimization of the reactional production conditions
}

\author{
José Renato de O. Lima ${ }^{1}$, Fabricia Gasparini ${ }^{1}$, Nadia de L. Camargo ${ }^{1}$, Yussra A. Ghani ${ }^{1}$, \\ Rondenelly B. da Silva ${ }^{2}$, José E. de Oliveira, ${ }^{1, *}$ \\ ${ }^{1}$ Center for Monitoring and Research of the Quality of Fuels, Biofuels, Crude Oil and Derivatives - \\ CEMPEQC - Organic Chemistry Department, Institute of Chemistry, , \\ São Paulo State University - UNESP, R. Prof. Francisco Degni s/n, Quitandinha, 14800-900, Araraquara, \\ São Paulo, Brazil. \\ ${ }^{2}$ Chemistry Department, Piauí Federal University - UFPI, Campus Ministro Petrônio Portela, Ininga, \\ 64049-550, Teresina, Piauí, Brazil. \\ * Corresponding author. Tel: +55 (16) 3301 9666, Fax: +55(16) 3301 9814, E-mail: \\ jeduardo.unesp@yahoo.com.br
}

\begin{abstract}
Indian-nut (Aleurites moluccana) and tucum (Astrocaryum vulgare) are oleaginous non eatable that present excellent oil content (about $60 \%$ and $30 \%$, respectively) compared to soy bean grains (20\%). Biodiesel production from these oils, using bioethanol as reactant, is an alternative for renewable energy source. In this paper, experimental design was used to determine the influence of these different kinds of oils on the transesterification reaction in order to evaluate the viability of biodiesel production process using ethanol as reactant. The most influential variables on the transesterification reaction yield were: alcohol to oil molar ratio, mass of catalyst, temperature and reaction time. In this paper, the variables was operated using experimental design with central composite. Compositional difference between both tucum and Aleurites oil has been verified by ${ }^{1} \mathrm{H}-\mathrm{NMR}$ and GC analysis. Physicochemical properties presented by Aleurites biodiesel are in accordance with ANP Regulation n. 07. On the other hand, the same conditions were not adequate to achieve a high transesterification yield from handmade Astrocaryum oil. In this case, better conditions were only obtained from refined oil. The reactional conditions optimized based on a kind of oil sometimes can't be suitable for any biodiesel production reaction.
\end{abstract}

Keywords: Biodiesel, Bioethanol, Aleurites, Optimization, Experimental design.

\section{Introduction}

Vegetable oils are one of the most commonly used biofuels raw materials. The main reason is their great versatility in the industrial transformation and environmental gains of their processing, in relation to petroleum, due to the absence of sulfur and heavy metals in their composition [1]. In this way, vegetable oils enable the production of biodiesel, a biofuel with very similar features as petrodiesel. The biodiesel is obtained from the chemical transformation of the oils (glycerides) by a transesterification process. In this case, the glycerides react with an alcohol of short carbon chain in the presence of a strong acid ou alkaline catalyst, to produce a mixture of fatty acid alkyl esters and glycerol [2].

The alcohol generally employed in transesterification reactions to biodiesel production is methanol, however, it presents some disadvantages, such as: mostly of it is obtained from non-renewable sources, presents high toxicity and Brazil do not produces sufficient amount for internal consumption. In other hand, ethanol, even deprecated due some reactional inconveniences, becomes very attractive under economic, strategic and environmental points of view; presents low toxicity and can be produced from sugar-cane, a highly renewable source. Brazil is currently the world's leader in bioethanol production obtained from sugarcane. Because of government subsidies, large sugarcane crops, and high sales taxes on gasoline, Brazil has built a profitable national bioethanol industry. Sugarcane is grown in the 
country as the climate presents perfect conditions for its cultivation and production. It is very easily converted to ethanol, and provides Brazil with huge supplies of bioethanol $[3,4]$.

Lima et al. $(2007 ; 2008)$ used bioethanol to prepare biodiesel from glycerides abundant in vegetable sources present in Brazil Midwest, North and Northeast regions, by homogenous catalysis reaching quantitative yield on catalytic process. These results became the motivation for a research aiming to overcome the reactional limitations for bioethanol and to improve its insertion into biodiesel energetic matrix.

Brazil has a lot of oleaginous vegetables with huge potential to produce biodiesel. The Aleurites moluccana seeds (so called indian nut or "noz-da-índia" in Brazil or "nogueira-deiguapé") has been employed as an oil source for several years. Aleurites is original from tropical Asia and pacific islands; In Brazil, it is broadly spread in Atlantic Forest. The species is a tree with $10 \mathrm{~m}$ eter height, that produces green fruits having one or two seeds. The percentage of oil extracted from Aleurites seeds is higher than soy bean grains, for example. It is about $63 \%$ composed of oleic glycerides that have excellent properties for biodiesel production. The oil obtained from Aleurites seeds is mostly used to make soaps, candles and varnish [6] and was already used to produce methylic biodiesel [7] but, to the best of our knowledge, there are no reports on its use to produce ethylic biodiesel.

There is a great biodiversity of palm trees in Brazil and among them there is a palm tree, Astrocaryum vulgare, Mart. (popularly known as "tucum" or "tucumã" in Brazil) not used as a source of oil for biodiesel production. The "tucum" is a palm tree that grows up to $10 \mathrm{~m}$ high, in a highly dry soil and those that floods occasionally. The almond supplies eatable white grease used to produce soaps, cosmetics and medicines. The fruits are very appreciated and the fruition occurs between November and May [8]. The "tucum's" mature fruits are yellow and consist of the pulp and the almond that correspond respectively to about $53.2 \%$ and $24.5 \%$ of the fruit weight [9]. The pulp produces orange oil $(18.18 \% \mathrm{w} / \mathrm{w})$ in which polyunsaturated fatty acids predominate and the almond produces a white grease $(29.59 \%)$ rich in lauric and myristic fatty acids. In Brazil it is possible to found the "tucum" tree in the Amazon and Northeast regions. The majority of its fatty acids consist of short chain, mainly lauric $(52.51 \%)$ and myristic $(25.04 \%)$. This property facilitates the kinetic of the transesterification reaction for biodiesel production leading to a product with more oxidative and thermal stabilities than biodiesel obtained from other oils, such as soybean [9].

As discussed earlier, nowadays, the optimization of biodiesel production mainly applying ethylic route, is of great relevance. The use of experimental design is a powerful tool to process optimization. The experimental design is a technique able to rationalize the application of experiments, to investigate, simultaneously, all potential variables that affect the results of a process. The advantages of working with experimental design are the achievement of more information using a smaller number of experiments, to perform studies about individual effect of each variable, how these variables interact independently and more than this, to analyze the results with a model that allows previsions of what will happen for any experiment into studied range. The response surface methodology, also, is a statistic tool for optimization based on factorial designs, to denote the response of the system, under study, with alterations in the variables [10].

According to Sarin et al. (2010), the properties of a biodiesel are influenced by the structure and amount of the component fatty acid esters, which depends on the oil source. So, the main objective of this work is to discuss the application of experimental design based on a specific 
oil to a different oil, for the production of biodiesel. Moreover, we intend to propose "tucum" and indian nut oils as raw materials for biodiesel production using the ethylic route. In such way we intend to improve the reactional conditions, using experimental design, to obtain biodiesel from indian nut seeds oil, by ethylic route ( $\mathrm{NaOH}$ as catalyst). Then, the best conditions should be applied to prepare biodiesel from almond oil of "tucum". Ester content, and other physico-chemical properties established by Resolution n. 07/2008, from Brazilian Regulatory Crude Oil, Natural Gas and Biofuels Agency [12], will be the principal reference parameters to verify the efficiency of reactional conditions obtained from experimental design.

\section{Methodology}

\subsection{Experimental design for ethylic biodiesel preparation from Aleurites oil.}

In order to obtain the response surface, it was applied an experimental design with central composite design. All variables: heating time, temperature, ethanol/oil molar ratio and mass of catalyst, were evaluated under five levels. These variables are shown in Table 1, together with their respective levels. A total of twenty six experiments were predicted. The results were analyzed using the software Statistica 7.0 [13].

Table 1. Variables and studied levels for the preparation of biodiesel from Aleurites seeds oil and ethanol ( $\mathrm{NaOH}$ catalyst).

\begin{tabular}{lccccc}
\hline \multicolumn{1}{c}{ Variables } & \multicolumn{5}{c}{ Level } \\
\cline { 2 - 6 } & $-1,41$ & -1 & 0 & +1 & $+1,41$ \\
\hline Heat time $/ \mathrm{min}$. & 50 & 70 & 90 & 110 & 130 \\
Molar ratio $/ \mathrm{ethanol} / \mathrm{oil}$ & $6: 1$ & $7: 1$ & $8: 1$ & $9: 1$ & $10: 1$ \\
Temperature $/{ }^{\circ} \mathrm{C}$ & 40 & 50 & 60 & 70 & 80 \\
Catalyst $/ \% \mathrm{w} / \mathrm{w}$ & 0.6 & 0,7 & 0,8 & 0,9 & 1,0 \\
\hline
\end{tabular}

\subsection{Materials, methods and instruments}

Ethanol (Synth, lot 118784) and sodium hydroxide (Qhemis, lot Q0011) of analytical grade were used without additional purification. Indian nut seeds were gathered at the city of Araraquara-SP, Brazil. The oil was obtained by milling the seeds and extracting the resulting material with hexane in a Soxhlet system during 10 hours. The yield was calculated dividing the final mass of oil extracted by the mass of the milled seeds. The "tucum" oil was obtained from the municipal district of Altos, PI, Brazil, and extracted by handmade way, in other words, it was extracted by milling and heating in water.

\subsection{Preparation of the tucum and Indian-nut biodiesel}

The transesterification of oils with ethanol, catalyzed by sodium hydroxide, were made using a three necked flask over a heating plate with magnetic stirrer. A condenser and a thermometer were connected to the flask. The third neck was closed with a rubber septum, through which the catalyst solution in ethanol was introduced using a syringe with a long needle under the heated ethanol/oil mixture surface. The reaction time began to be counted from this moment. The reaction mixture was kept in the flask under magnetic stirring. After the reaction time be completed, the final products were separated by centrifugation and the biodiesel (upper phase) was washed with distilled water. The biodiesel was, then, dried by heating at $60^{\circ} \mathrm{C}$ about 40 minutes under argon flow. 


\subsection{Physicochemical characterization of the tucum and Indian-nut biodiesel}

The "tucum and Indian nut biodiesels were characterized by: visual aspect; ${ }^{1} \mathrm{H}$ NMR spectra; viscosity at $40{ }^{\circ} \mathrm{C}$ (ASTM D445), specific gravity at $20^{\circ} \mathrm{C}$ (ASTM D4052), cupper corrosivity (3h at $50{ }^{\circ} \mathrm{C}-\mathrm{ASTM}$ D130); cold filter plugging point (ASTM D6371), acidity index (ASTM D664); ester content (EN/ISO 14103); free and total glycerol and glycerides index (EN 14105); iodine index (EN 14111), water content measured by the Karl Fisher method (ASTM D6304), content of sodium, potassium, calcium, magnesium and phosphorus (ICP-OES NBR 15553) and oxidative stability analysis (Rancimat - EN 14112).

${ }^{1} \mathrm{H}$ NMR spectra were obtained in a equipment Varian Inova of $500 \mathrm{MHz} . \mathrm{CDCl}_{3}$ was applied as solvent ( $30 \mu \mathrm{L}$ of sample and $600 \mu \mathrm{L}$ of solvent). ${ }^{1} \mathrm{H}$ NMR spectrum was obtained at $300 \mathrm{~K}$ temperature using 64000 acquisitions with pulse standard (s2pul), and tetramethylsilane TMS as reference. The spectral profile was used to observe the conversion of oil to biodiesel and to verify the oils composition.

\section{Results / Discussion}

Aleurites moluccana presented fruits with a high content of oil $(60 \%)$, such as found in other researches [7]. Tucum, how presented in the introduction [9], can produce around $30 \%$ of oil. This yield is better than soybean that shows an oil content around $25 \%$, for example.

\subsection{Experimental design for Aleurites biodiesel synthesizes}

After all of the twenty six experiments and measure the ester content were done, were built six surface designs where the $\mathrm{Y}$ axis represents the percentage of ester content. The best results was obtained employing heat time about 90 minutes, molar rate alcohol/oil 8:1, temperature of $60{ }^{\circ} \mathrm{C}$ and $0.8 \%$ of catalyst. Was reached more than $99 \%$ of conversion. However, we can see other conditions that could be applied considering the little difference at the final results. In other words, when employed 70 minutes; $9: 1$ molar rate; $60{ }^{\circ} \mathrm{C}$ and $0.8 \%$ of catalyst we achieved nearby $100 \%$ of yield. These conditions were used to synthesize both Indian-nut and Tucum biodiesel.

\subsubsection{Preparation of the tucum and Indian-nut biodiesel}

It is necessary remember that the oils are from different sources and they were obtained by different process too. The optimization process has been done employing Indian-nut oil only. Exactly $100 \mathrm{~g}$ of oil was put into a flask and heated until $60^{\circ} \mathrm{C}$. After then, was added the ethylic alcohol containing the total mass of catalyst. There were not troubles during the reactional time. The purification process was done using distillate water at room temperature. It was around $30^{\circ} \mathrm{C}$. No special process was necessary to segregate the glycerin phase.

\subsection{Physico-chemical characterization of the tucum and Indian-nut biodiesel}

Physico-chemical properties showed that both biodiesel were very similar at rheological viewpoint, because their viscosity and density are practically equals. Table 2 shows analysis results. The water content proves the efficiency of drying process using argon gas. It was below the maximum limit of $500 \mathrm{ppm}$. Some ions level like sodium, potassium, calcium, magnesium and phosphorus are below quantification limit of ICP equipment. That way, the biodiesel are in accordance to ANP Resolution. The tucum biodiesel's low iodine index (14.6 $\mathrm{g} / 100 \mathrm{~g})$ denotes his saturated character and hence his cloud point $\left(5.0^{\circ} \mathrm{C}\right)$ will be bigger than Aleurites biodiesel $\left(-5.0^{\circ} \mathrm{C}\right)$. The iodine index of Aleurites biodiesel $(150.36 \mathrm{~g} / 100 \mathrm{~g})$ reflects a high level of unsaturated chains on his composition. These unsaturated chains can resist lower temperatures than the saturated compounds without freezing. 
Table 2. Aleurites and Tucum biodiesel physicochemical parameters.

\begin{tabular}{|c|c|c|c|c|c|}
\hline \multirow[t]{2}{*}{ PARAMETERS } & \multirow[t]{2}{*}{ UNIT } & \multirow[t]{2}{*}{ LIMIT } & \multirow[t]{2}{*}{ METHOD } & \multicolumn{2}{|c|}{ RESULTS } \\
\hline & & & & Tucum & Aleurites \\
\hline Aspect & - & LII* & Visual & LII & LII \\
\hline Density at $20^{\circ} \mathrm{C}$ & $\mathrm{kg} / \mathrm{m} 3$ & $850-900$ & ASTM D4052 & 0,8770 & 0,8789 \\
\hline $\begin{array}{l}\text { Kinematic viscosity at } \\
40^{\circ} \mathrm{C}\end{array}$ & $\mathrm{mm} 2 / \mathrm{s}$ & $3,0-6,0$ & ASTM D445 & 4,54 & 4,12 \\
\hline Water mass, max. & $\mathrm{mg} / \mathrm{kg}$ & 500 & ASTM D6304 & 261,6 & 160,1 \\
\hline $\begin{array}{l}\text { Sodium + Potassium, } \\
\text { max. }\end{array}$ & $\mathrm{mg} / \mathrm{kg}$ & 5 & NBR 15553 & $<\mathrm{LQ}^{* *}$ & $<\mathrm{LQ}$ \\
\hline $\begin{array}{l}\text { Calcium + Magnesium, } \\
\text { max. }\end{array}$ & $\mathrm{mg} / \mathrm{kg}$ & 5 & NBR 15553 & $<\mathrm{LQ}$ & $<\mathrm{LQ}$ \\
\hline Phosphorus, max. & $\mathrm{mg} / \mathrm{kg}$ & 10 & NBR 15553 & $<\mathrm{LQ}$ & $<\mathrm{LQ}$ \\
\hline $\begin{array}{l}\text { Cupper corrosivity, } 3 \mathrm{~h} \\
\text { a } 50^{\circ} \mathrm{C} \text {, max. }\end{array}$ & - & 1 & ASTM D130 & $1 \mathrm{a}$ & $1 \mathrm{a}$ \\
\hline $\begin{array}{l}\text { Cloud filter point pour, } \\
\max \text {. }\end{array}$ & ${ }^{\circ} \mathrm{C}$ & 19 & ASTM D6371 & 5,0 & $-5,0$ \\
\hline Iodine índex & $\mathrm{g} / 100 \mathrm{~g}$ & Anotate & EN 14111 & 14,67 & 150,36 \\
\hline Free glycerin & $\%$ mass & 0,02 & EN 14105 & 0,00 & 0,00 \\
\hline
\end{tabular}

* Impurities free and limpid.; ** LQ: Quantification limit.

Total glycerin and glycerides content are not displayed because they are a parameter directly linked to ester content. Thus, in the tucum biodiesel we can not expect them are according to maximum limit due tucum ester content is only $79.8 \%$. In other hand, total glycerin of Aleurites biodiesel $(0.075 \%)$ was completely in agreement with that limit which can not be more than $0.25 \%$ of total glycerin. Free glycerin is an important parameter, especially in order to provide information about purification process. In this case, two biodiesel presented non quantitative mass of glycerin due to efficient washes.

\section{3. $\quad{ }^{1} \mathrm{H}$ NMR biodiesel analysis}

When comparing indian nut and "tucum" biodiesels ${ }^{1} \mathrm{H}$ NMR spectra (e.g. Fig. 1 and 2) is possible to see differences, such as unsaturation level and compositional profile. Absence of representative peaks around $2.1 \mathrm{ppm}$ in "tucum" spectrum, assigned to the methylene protons attached to the unsaturated carbon, shows its high degree of saturation.

Beyond this, near to $5.3 \mathrm{ppm}$ the peak assigned to the $\mathrm{H}$ from $\mathrm{CH}$ unsaturated is in agreement with the previous observation about pi bonds. In the Glycerides chains presents in tucum biodiesel there is almost none pi bond beyond those of carbonyl groups. Observing chromatograms overlap (e.g. Fig.3), we can note the real composition`s difference between both oils and biodiesel from tucum and Aleurites. 
Figure 1. ${ }^{1} \mathrm{H}$ NMR Aleurites biodiesel spectrum.

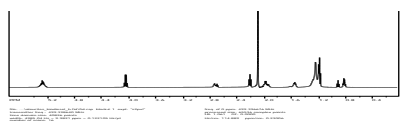

Figure 2. ${ }^{1} H$ NMR "tucum" biodiesel spectrum.

\subsection{Ester content}

One of the most important reactional results is the ester content. This parameter represents how efficient was the reactional process. The principal target of this paper is to show how useful can be the optimization from an experimental design in order to apply it to others oils with different properties. If the ester contents yield are similar, so these same conditions could be applied. The Aleurites biodiesel synthesize presented yield about 99\%. This result is almost the same as the one previously obtained during the optimization process. When those reactional conditions were applied to synthesize ethylic tucum biodiesel, the result achieved was only $79.8 \%$ for ester content. The minimum level described on Brazilian national legislation is $96.5 \%$.

The chromatograms superimposed, e.g. Fig. 3, shows the composition differences between biodiesels from "tucum" and indian nut in terms of carbon chain length. In order to prove this, some ethylic ester standards were run on GC and their retention time (RT) were registered: $\mathrm{C} 8: 0, \mathrm{RT}=2.5 \mathrm{~min}$; $\mathrm{C} 12: 0, \mathrm{RT}=7.0 \mathrm{~min} ; \mathrm{C} 14: 0, \mathrm{RT}=8.0 \mathrm{~min}$; $\mathrm{C} 17: 0, \mathrm{RT}=14.2$ and $\mathrm{C} 24: 1$, $\mathrm{RT}=25.4 \mathrm{~min}$. With this data, we can prove the saturated character of tucum oil. In the chromatogram could be seen that the majority of compounds from tucum biodiesel are between 2.5 and 15.0 minutes. In this interval there are C8:0, C10:0, C12:0, C14:0 and C16. Even a little after that, there are some peaks attributed to $\mathrm{C} 18: 0$, or a small peak assigned to C18:1, but nothing after 17.5 minutes. Regarding Aleurites, most peaks are above $12.0 \mathrm{~min}$ and below $18 \mathrm{~min}$. That interval covers saturated and unsaturated chains like C16:0, C18:0, $\mathrm{C} 18: 1, \mathrm{C} 18: 2$ and C18:3. Among those peaks, majority lies above 15.0 minutes, region of occurrence of peaks corresponding to esters with more than 17 carbons. 


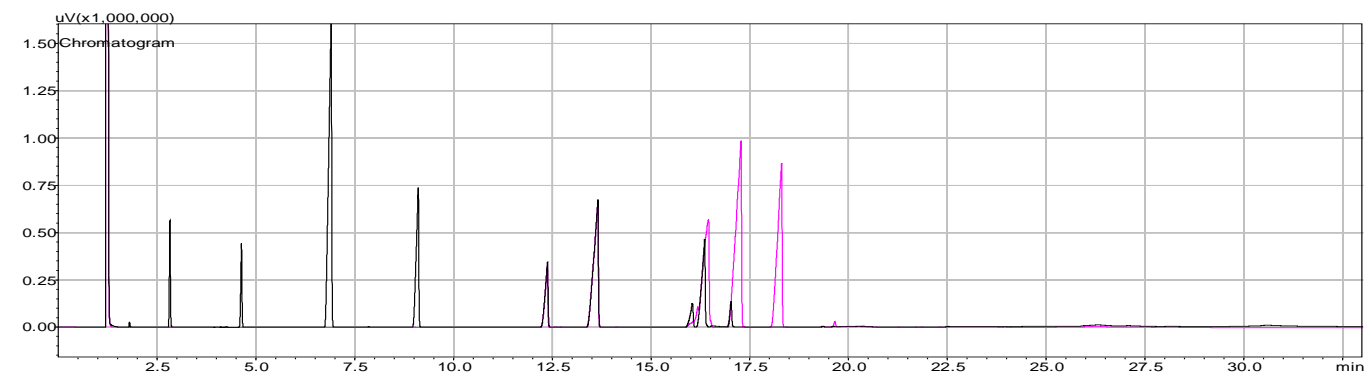

Figure 3. Superimposed "tucum" and indian nut biodiesels chromatograms (pink: Indian-nut biodiesel; black: tucum biodiesel.

\section{5. “Tucum" biodiesel preparation yield under the best conditions found to indian nut biodiesel preparation.}

The yield achieved to "tucum" biodiesel prepared, applying the best conditions developed by experimental design on indian nut oil, was very low. The preparation procedures were the same to both oils. Only during work up p rocedures there were some differences between them. Because of the acidity presented by "tucum" oil (soap generation) and its shorter carbon chains, the washing process generated more emulsions than during indian nut biodiesel work up; "tucum" biodiesel was washed much more times to remove soap excess and to break any emulsions. This can be one of the causes for the low yield of esters obtained from "tucum" oil. Other causes for the unsuitable behavior of "tucum" oil under the best experimental conditions developed for indian nut oil conversion to biodiesel may be its impurities, not removed during manual oil extraction process, and the manual oil extraction itself.

\section{Conclusions}

The oil content of "tucum" and indian nut seeds is greater than soybean grain. Ethanol showed technically suitable as a reagent to biodiesel production from indian nut and "tucum" oils. Indian nut oil has considerably more unsaturated esters than "tucum" oil, what explains its lower resistance to oxidation. Experimental central compound design and surface response methodology were efficient for optimization of the reactional conditions (time, temperature, molar ratio ethanol/oil and mass of catalyst) to obtain biodiesel from ethanol and indian nut oil. The optimized conditions led to an almost stoichiometric yield of biodiesel confirming the forecast of the technological viability of indian nut oil to obtain high yields of ethylic biodiesel. The same optimized conditions did not apply for "tucum" oil. Further experiments with "tucum" oil obtained by the same extraction procedure used to indian nut oil are necessary. Experimental design is an important tool to optimize chemical preparations. However, its relationship with raw materials characteristics must be carefully observed.

\section{References}

[1] Lee, S. W.; Herage, T.; Young, B. Emission reduction potential from the combustion of soy methyl ester fuel blended with petroleum distillate fuel. Fuel (83), 2004, pp. 16071613.

[2] Lima, J.R.O., Silva, R.B., Silva, C.C.M., Santos, L.S.S., Santos Jr, J.R., Moura, E.M., Moura, C.V.R. Biodiesel de babaçu (Orbignya sp.) obtido por via etanólica. Quimica nova 30 (3), 2007, pp. 600-603.

[3] BRASIL. Serviço Brasileiro de Apoio ás Micro e Pequenas Empresas (SEBRAE). Cartilha Biodiesel 2009. A vailable from: http://www.biodiesel.gov.br/docs/Cartilha_Sebrae.pdf. 
[4] http://www.energyrefuge.com/archives/largest-ethanol-producer.htm, accessed in December 13, 2010

[5] Lima, J.R.O., Silva, R.B., Moura, E.M., Moura, C.V.R. Biodiesel of tucum oil, synthesized by methanolic and ethanolic routes. Fuel (87), 2008, pp. 1718-1723.

[6] Ojasti, J; Jiménez, E.G., Otahola, E.S., Román, L.B.G. Informe sobre las Especies Exóticas em Venezuela. Caracas, Venezuela, Ministerio del Ambiente y de los Recursos Naturales. 2001. A vailable from: www.institutohorus.org.br/download/fichas/Aleurites_moluccana.htm.

[7] Azam, M.M., Waris A., Nahar N.M. Prospects and potential of fatty acid methyl esters of some non-traditional seed oils for use as biodiesel in India. Biomass \& Bioenergy (29), 2005, pp. 293-302.

[8] http://www.vivaterra.org.br/palmeiras_nativas.htm\#tucuma, accessed in December 13, 2010

[9] Mambrim M.C.T, Arellano D.B. Caracterización de aceites de frutos de palmeras de la región amazónica del Brasil. Grasas y Aceites 48 (3), 1997, pp. 154-158.

[10]Baptista, P., Felizardo, P., Menezes, J.C., Correia, M.J.N. Multivariate near infrared spectroscopy models for predicting the methyl esters content in biodiesel. Analitica Chimica Acta (607), 2008, pp. 153-159.

[11] Sarin, R., Sharma, M., Khan, A.A., 2010. Terminalia belerica Roxb. seed oil: A potential biodiesel resource. Bioresource Technology (101), 2010, pp. 1380-1384.

[12] AGÊNCIA NACIONAL DO PETRÓLEO., 2008. Resolução ANP nº. 07. Diário Oficial da União (DOU), 20 mar. de 2008.

[13]Ryan, T. P. Modern Experimental Design. John Wiley \& Sons. New Jersey, 2007. 